\title{
Understanding Snacking through a Practice Theory Lens
}

\begin{tabular}{|c|l|}
\hline Journal: & Sociology of Health and IIlness \\
\hline Manuscript ID: & SHI-00193-2014.R1 \\
\hline Manuscript Type: & Original Article \\
\hline Subject Area: & $\begin{array}{l}\text { Diet < RESEARCH AREAS, Food < RESEARCH AREAS, Health behaviour < } \\
\text { RESEARCH AREAS }\end{array}$ \\
\hline Abstract: & $\begin{array}{l}\text { This article approaches snacking from a practice theory perspective in } \\
\text { order to understand how this reframing may afford new insights. In doing } \\
\text { so it also contributes to sociological thinking on eating practices and their } \\
\text { reproduction as well as reflecting upon the ontological assertions of } \\
\text { practice theory and its theory of social change. In particular this article } \\
\text { argues that the re-conceptualisation serves to clarify a sociological } \\
\text { research agenda for eating practices associated with snacking. It is argued } \\
\text { that setting snacking within routine temporalities and spatialities and as } \\
\text { bound up in the recursivity between practices and relations is especially } \\
\text { important for thinking about snacking sociologically. In common with } \\
\text { applications of practice theory in the field of sustainability transitions the } \\
\text { aim is to move beyond individualistic assumptions of behaviour change and } \\
\text { instead situate snacking as an eating practice with health implications that } \\
\text { has emerged within the social, temporal, economic and cultural } \\
\text { organisation of everyday life. }\end{array}$ \\
\hline \hline
\end{tabular}




\section{Understanding Snacking through a Practice Theory Lens}

\section{Introduction}

Shadowed pejoratively by meanings of unruly, infantile eating and through further associations with excess and 'junk food', the practice of snacking is a complex moralised activity to grasp. To 'graze' implies animalisation, a fall from the 'civilised' structure of bounded meal times. It is difficult to speak of snacking without this baggage. As fears over mooted obesity epidemics have grown in recent decades (Guthman and DuPuis 2006) there is now considerable scientific and health-related literature on snacking which has risen exponentially in recent decades. Eating practices in the UK are now subject to further scientific and policy scrutiny owing to their enmeshment in contemporary concerns over energy and water resources and in urgent interrelated crises of food security and climate change (Lang 2009).

The aim of this article is to take a fresh approach by thinking about snacking using the insights of practice theory. This offers an opportunity to reframe snacking and to think somewhat differently about how the practice is reproduced. Although this article takes a somewhat neutral stance on whether 'snacking' is deserving of its moralised status, practice theory does offer potentially novel modes of intervention that might improve health and other outcomes (see Blue et. al. 2014). However this is not the focus of this article which instead is to consider the sorts of research directions that the conceptual work of practice theory might open up in the case of snacking. 
The aims here are potentially fraught since the conceptual approach of practice theory could perhaps be seen as just as nebulous as the substantive focus upon snacking practices. As an approach it draws upon a rich and varied sociological and philosophical heritage. Nevertheless practice theory has recently begun to coalesce, largely in the context of European social science work upon sustainability transitions (e.g. Røpke 2009, Shove et. al. 2012), into a body of work that does specific ontological labour in its conceptualisation of the social and is critical of individualistic approaches in its understanding of intervention and social change. A practice focus on snacking is arguably timely as some of those same scholars who have used the framework to better understand sustainability transitions have recently turned their explicit attention to health practices (Blue et. al. 2014). Such work dovetails well with a recent special issue in this journal arguing that social scientists should switch frames from health behaviours to health practices (Cohn 2014; see also Delormier et. al. 2009). Although the special issue failed to engage with the breadth of sustainable practices literature it shares a desire to comprehend the everyday in sociological terms. Similarly, this article positions itself against research on snacking understood as an individual behaviour (e.g. Grogan, Bell \& Conner 1997; Weijzen, de Graaf \& Dijksterhuis 2009; Verplanken 2010), instead viewing snacking as a set of eating related practices that emerge out of the social organisation of everyday life. At the outset it is necessary to outline the main tenets of practice theory especially for how it can be used to think about food and snacking practices in particular.

\section{Practice Theory and Eating}

Treating practices rather than individuals or institutions as the primary unit of enquiry, considering how they consolidate and change is the focus of practice theory. Here I follow 
the conceptualisation by Shove et. al. (2012) of practices comprised of three elements competency, materiality and meaning. Competency refers to skills and know-how, materiality to the broad array of objects, bodies and technologies that comprise a practice, and meanings refer to ideas, affect, aspirations, norms and symbolic meanings (ibid. p.14). This is a simplification of previous definitions (e.g. see Reckwitz 2002: 249) and perpetuates the practice theory ontological shift that elements are "qualities of a practice in which the single individual participates, not qualities of the individual" (Reckwitz 2002: 250). In this posthumanist inflection people are reframed as 'carriers' of practices (ibid.). Posthumanism has been part of the theoretical discussion of the 'practice turn' (see Pickering 2005) and is part of the sociological ontological shift away from the individual in practice theory and other frameworks such as actor-network theory. Shove et. al. argue that "practices emerge, persist, shift and disappear when connections between elements of these three types are made, sustained or broken" (2012: 14-5 original emphasis). All food related practices have historical trajectories and many become socially recognisable and normative. For example, in British culture (the main focus of this article) the 'Sunday roast' constitutes one traditional meat eating practice that involves interdependent skills (e.g. preparation, carving), materialities (an oven, a tray, a dead bird or joint, a butcher or supermarket) and shared meanings (common aesthetic, affective, moral and cultural understandings) that have coalesced to form what practice theorists refer to as the practice-as-entity (e.g. Shove et. al. 2012: 7). The actual doing of the practice in everyday life is referred to as the practice-asperformance.

An opening contention is that a practice theory approach to eating is complementary in certain ways to much scholarship in the social science of food. The above threefold definition of a practice develops the often repeated assertion that eating is both a material and symbolic 
activity, further stressing the importance of everyday competences as significant to the coherence of practice. This is a coherence that is further dependent upon the affective and political relationalities between carriers of a practice. Practices we are reminded give spatial and temporal substance to our social fabric (Shove et. al. 2012: 133). Such points resonate with everyday eating practices as this article explores in the case of snacking. In their recent volume Why We Eat How We Eat: Contemporary Encounters Between Foods and Bodies Abbots \& Lavis present a suitably broad frame for understanding eating -

\begin{abstract}
"Eating, as a conceptual and a physical act, brings both foods and bodies into view; food...is placed in the mouth, chewed, tasted, swallowed and digested. Its solidity is thus broken down and rendered into fragments that both pass through, and become, the eater's body. This is a process that concomitantly establishes and ruptures social relations between bodies, whether those of the food's producers, retailers, micro-biological components or even of the original animal sources. Unpacking the encounters between foods and (human and nonhuman) bodies then, offers a way to take account of the many networks and relations embedded in and performed by eating" (Abbots and Lavis 2013: 1).
\end{abstract}

This way of framing eating found in contemporary critical food studies with its stress on relationalities, multiples scales, affect and the more-than-human is cognate with the ontological moves of the practice turn. Moreover practice theory recognises the corporeality of the social by emphasizing how the embodied performance of a practice in multiple sites reproduces and connects the three elements. Bodies themselves contribute significantly to the materiality of practice and Reckwitz asserts that "a practice can be understood as the regular, skilful 'performance' of (human) bodies” (2002: 251). 
Practices constitute the mundane habits of everyday life and may disappear from both immediate reflection and individual control. Yet it is here also that such links may erode, become detached and ultimately a practice may fade from social life. The case of the Sunday roast for example may be one such practice that is losing practitioners and is no longer as central to weekend routines as previously. In the case of snacking an arguably significant change in the practice has been the emergence of companies producing 'healthy snacks' constituting an innovation in the practice as performance. It could be anticipated that this has the potential to erode the prevailing moralistic meanings of snacking and change the practice entity accordingly.

As the unit of inquiry practices are intended to cut across traditional sociological demarcations of scale such as micro and macro. Thus Shove et. al. (2012) orient themselves to understandings of the extent to which given practices are embedded by arguing that connections form between practices themselves, forming what they term 'bundles', an example might be snacking and watching television. When such bundles become part of routine social infrastructure we encounter practice 'complexes'.

Practice theory is a call to understand the dynamism of elements in a practice. Practices are constantly changing although new element configurations can create quite abrupt change. This attention to temporal flow foregrounds the importance of historical analysis for thinking through the biography of elements, practices, bundles or complexes. Shifting meanings, new materials and new forms of competency change practices and render some redundant. Such elements can become reincorporated into new practices such as the disappearance of 'elevenses' and its replacement by cups of tea or coffee throughout the day. Redundant elements, like niche elements or practices, are potential resources for thinking about 
processes of adoption and transition. In addition to changing elements, practices can change when those they may be bundled together with also change.

Furthermore, although the primary conceptual focus on practices may suggest a posthumanist decentring of social actors whereby the 'individual' is seen more as a mobile intersection of practices and relationships, our 'doings', our performances, and so our agency working with that of other materialities, the networks we form, remain important for understanding practice transitions. Thus the way in which populations of carriers might change can be important for the normalisation or the degeneration of a practice. If the lifecourse or 'career' (Shove et. al. 2012) of practices play out via links between its elements then traditional sociological foci upon social relations, questions of power and political economy (see Sayer 2013) remain vital to understanding the making and breaking of such links and so the waxing and waning of practice trajectories.

In approaching food sociologically and through a practice theory lens we are faced with various conceptual issues. The simple everyday practice of eating intersects with bundles of other practices, notably shopping, transport, storage and cooking practices. Eating is part of the materiality of the social itself featuring clearly in the everyday performance of social relationships. Eating is also part of doing leisure, doing work, or doing family (Morgan 2011), and shapes and re-shapes meanings of class, gender, sexuality and nation (Probyn 2000: 32). Moreover invisible to most food consumers are the wide array of production practices, modes of distribution shaping and shaped by sets of international standards, trade relationships, governance and the political economy of food. Eating practices when examined in this way shape the temporalities and spatialities of everyday life. They are thus diffuse and multi-faceted. Practice theory via its three way conceptualisation of a practice 
makes clear that modes of eating such as snacking must be viewed as significantly exceeding the immediate act of placing food in one's mouth even as it simultaneously wants to highlight such moments of bodily performance as empirically important. In the area of energy consumption some practice theorists approach energy not as something used for its own sake but as part of accomplishing social practices at home, at work and in moving around ${ }^{1}$. Food arguably is not quite as amenable to this framing. Whilst eating practices certainly accomplish and lend meaning to a wide array of other practices they also have a sensual aesthetic of their own. Food is a symbolic and material resource. Many snacks are pleasurable and may be something to look forward to during the day. The materiality of foods also has agency in the recruitment of practitioners and constitutes part of the social, defined in more than human terms. This broadening out of the social to include a consideration of materialities as an important element of practice reflects developments in social theory acknowledging the way that "social relations are 'congealed' in the hardware of daily life" (Shove et. al. 2012: 10).

Sociologist Alan Warde has argued that eating practices are difficult to study since they are not necessarily co-ordinated and regulated in the same manner as other practice entities. Warde is interested to understand just what sort of practice eating is ${ }^{2}$. He gives the example that in the UK there is no shared sense of what it means to eat well and there are no shared standards governing eating practices (2013: 22). The practice of eating varies culturally and historically because its degree of social organisation shifts within different social and economic conditions or complexes. Contemporary attempts to create a definition of a 'sustainable diet' could be seen as a new attempt to morally codify eating practices arising out of tensions between capitalist economic practices and ecological sustainability. Warde defines the codification of practices as "a matter of specifying the objectives or purposes in 
view in a domain of activity, and the ways to go about attaining such goals" (2013: 23). Such codification manifests itself in sociologically interesting phenomena such as manuals, rule books and formal organisations. He argues these are generally lacking in the area of eating practices, describing contemporary eating as socially weakly organised (p.25). Certainly the degree of codification will shape the sort of strategies and methodologies sociologists might pursue in order to investigate a given practice. However, Warde's argument is perhaps overstated and does not disqualify eating from a social practice approach. Importantly he is not absolutist here, writing

"Arguably, the current disorganization of eating is historically specific. Its component integrative practices have evolved over many decades, even centuries, but have come together sufficiently for eating to be recognizable, 'out there' in performances. In some circumstances they come together to constitute an entity, which is socially coordinated in such a manner that an organized nexus can be identified"

(Warde 2013: 25).

These comments are relevant to an eating practice like snacking. It is hard to think of manuals or rule books or associations that cohere and codify snacking ${ }^{2}$. It can also be challenging to define the boundaries of a snack eating event. Yet simultaneously snacking and snacks are socially recognised and are embedded within the everyday eating practices of most people. Shops often have snack sections and there tend to be socially shared meanings over what constitutes a snacking event. With so many practitioners and its performance relatively simple to discern temporally snacking is indeed empirically intelligible. Perhaps what Warde's comments capture is that eating practices are constantly changing according to their complex relationships with other practices. This raises methodological challenges for 
social science and for the conceptualisation of a specific practice. But practice theory is exactly a process approach designed to apprehend the dynamics of the social. Difficulties within the conceptualisation of snacking as a practice may relate then to its contemporary state of transformation.

\section{A Practice Conceptualisation of Snacking}

The wealth of scientific research into snacking alluded to above features a range of approaches to defining snacking. Some studies take for granted a common sense temporal definition of snacking as eating outside meal times (Savige et. al. 2007). Others (e.g. McCrory and Campbell 2011) acknowledge some definitional complexity around the way in which foods commonly assumed to be healthy (such as an item of fruit) are also defined as snacks and how eating practices exhibit significant cultural variability. Some approaches adopt a food-based classification system based on core food groups and non-core food groups (MacDiarmid et. al. 2009) though this may be confused by material overlap such as snacking on meal leftovers. A study on the use of 'snack', 'snacking' and 'eating snack food' in the UK found ambiguous and different uses of these terms and while they all referred more often to eating outside mealtimes there was more overlap between the use of 'snack' and the meal of lunch (Chamontin et. al. 2003). In using practice theory this article aims to show how this conceptual issue of definition can be clarified by considering relations between practices, deconstructing the practice in terms of its constituent elements, situating snacking temporally and spatially and underlining the historical contexts and emergence of snacking. The intention is that this can then be of use to empirical work on everyday eating practices associated with snacking. 
Food sociologists point to the potential social weakening of formal meal times via a process of informalisation (Southerton 2006: 439) or destructuration (Warde and Yates 2014, Mestdag 2005). Destructuration refers to a loss of temporal fixity of eating events, a spatial diversification of eating sites and a social destructuration with an increase in solitary eating events (Mestdag 2005). Empirical support for this thesis (e.g. Jackson 2009: 10) points to snacking as a new and significant eating practice. As further possible evidence we could look to the erosion of the meal by snacking in terms of a process of 'practice colonisation' in some contexts. In some daily routines breakfast and lunch could increasingly be described as 'snack like' calling into question a simplistic relational definition of snacking vis-à-vis the meal. It is common for lunch to be consumed in the office in front of the computer as a material assemblage of snacks such as a sandwich, drink and so on. Indeed a sandwich has a liminal quality as to whether it is seen as a snack or a meal which may depend upon whether it is accompanied by other foods. Cereal companies have diversified their products into snacks so that breakfast can be mobile, consumed during the morning commute or as one arrives at work. Examples include the breakfast bar by Jordans and breakfast biscuits by both Belvita and Kellogg's. This represents a marketing strategy by these companies presumably aimed at consumers lacking in the time resources or inclination to sit down for breakfast. These 'breakfast snacks' have come under some media criticism for their high sugar and fat content illustrating also perhaps how the transgression of the boundary between 'meal' and 'snack' risks exposure to the latter's cultural moralisation ${ }^{3}$. Framed in terms of practice theory this degree of definitional overlap between 'meal' and 'snack' takes place via an innovation in the materiality of food itself and a subversion of the temporally normative meaning of the snack away from its common sense understanding as taking place outside meal times. This could be contrasted with the tendency for some to have cereal late at night as a snack which retains the materiality of the breakfast but sees it become a snack due to its 
temporal shift. Part of destructuration may also be an erosion of the normative culturally situated practice of eating three meals a day. Those who skip breakfast may focus on two or even one main meal a day augmented by other eating events. There is cultural variation here, for example, some people in French society eat a small fourth meal consumed between traditional lunch and dinner times called a goûter (McCrory and Campbell 2011: 145).

It is helpful to think about the conceptualisation of snacking by thinking in more detail about the three elements that make up the practice. Firstly, in considering the wide array of meanings of snacking something of the moralisation and temporal norms of the practice have already been noted. A snack has typically been seen as less nutritionally adequate than a meal. Thinking a little more closely about the temporal relationality between snacks and meals a snack is sometimes thought of as providing a bridge between meal times which is a more positive meaning. Moreover snacking is strongly associated with pleasure but perhaps also a wider affective experience including guilt, anxiety or jealousy. Doing particular sorts of snacking might be bundled with more healthy sporty practices as much as with more sedentary habits. A substantial amount of snacking research looks at the co-location of snacking with such practices as television viewing or gaming. Yet other snacks may evoke meanings of cultural (be)longing or suggest childhood memories. As well as the surfacing of a healthy snacking industry some snacks may attempt to carry meanings related to forms of ethical consumption such as reduced environmental impact.

Secondly, the materialities of snacks are smaller, portable, often packaged and available from a wide range of shops. Particular forms, such as some healthier snacks, may be found in more specialist retail infrastructure. Snacks can be sweet or savoury. Drinks interestingly are not usually referred to as snacks unless accompanied by food. Sweet snacks are more likely 
to be seen as a 'treat', perhaps a special kind of snack often couched in terms of self-reward. Here the role of manufacturers in the development of taste and its cultural circulation and stratification in interplay with human corporeality should not be discounted from thinking about the sensual enrolment of new practitioners in a wider range of snacking practices. The whole production complex of snacks, their design and distribution are vital to the everyday performance of snacking. Historically snacking has also had its own specific materialities especially in the form of the vending machine. Although certainly a material element shared by many (non-food) practices, the proliferation of the vending machine throughout the twentieth century co-evolved with new institutional spaces and transport hubs and may arguably be tied to less temporal and spatial structure in eating practices. Snacking practices are also dynamically in relation with the materiality of meals. If meals are composed in such a way so as not to be experienced as filling then this could increase the likelihood of snacking. Similarly the bundling of eating practices with others that require significant energy expenditure may shape the practice of snacking. For example, there is a subset of high sugar snacks that are marketed at people involved in sports and exercise.

Thirdly, snacking competences are less clear than the other two elements of the practice. This is because the design of the snack is to build competence into the materiality of the food itself. Although there are niche innovations in the practice to make homemade snacks the rationale for most snacks is that they are time saving, convenient and ready to eat. The knowhow required to practice snacking is thus limited in most cases to knowledge of sources and of new snacking innovations. Forms of social competency around when, where and with whom it is normatively appropriate to snack are also important and form an important link between competency and meanings. 
Having considered the elements of snacking we can add some further depth to this discussion by thinking about snacking in relation to recent work on practices and temporality (Southerton 2006, 2012). Unlike other practices that are also frequent and repeated the periodicity (Southerton 2006) of eating practices is in a sense inescapable. However the temporal organisation of eating practices is open to much elaboration. Temporality is intuitively important to thinking about snacking. It is not only the case that the snack is defined by being materially smaller than the meal but that it takes place at times not normally seen as meal times. Thus although as I have argued we should not be content with a simplistic temporal dichotomy between meal and snack, empirically certain times of the day - mid-morning, mid-afternoon and later at night - are most likely be those times at which most snacking practices take place. However we can also point to a certain temporal ambiguity. For example, if a sweet foodstuff is consumed perhaps ninety minutes after dinner can it still be claimed as a dessert linked to a meal or has it become a snack?

In the practice theory literature practices are often described as 'routines' or 'habits' though without further specification of what that might mean. Sociologist Dale Southerton aims to add analytical rigour in order that we better grasp temporalities and the reproduction of practices. He argues simply that,

"Habits and routines reflect stable practices as entities that permit and are reproduced through recurrent, non-reflexive and culturally shared actions. Explained this way habits and routines are the observable patterns of action that result from the reproductive performances of stable practices"

(Southerton 2012: 15/6). 
This is important to practice theory overall since it helps to underline its opposition to theories that may conceptualise social actors as always self-knowing and rational. Southerton further specifies habits and routines by outlining three forms of action that are generally evoked by the terms. These are

"dispositions - the tendency to perform practices according to culturally derived orientations; procedures - tacit knowledge and embodied skills; and sequences - the ordered performances of practices through material, infrastructural and institutional forms"

(Southerton 2012: 16).

Dispositions are intended to capture how different groups in society are differently disposed toward practices, the importance that might be endowed in a practice and thus the time spent performing it. This includes a consideration of economic and cultural capital and also the observation that some social groups may also hold a different relation to time itself, for example, everyday schedules that exhibit a high degree of planning and busyness. If one is generally enmeshed in rushed schedules one may be more likely to be recruited to snacking practices. Southerton also points out that if a particular practice comes to provide meanings of self-actualisation carriers of that practice may come to organise their lives in order to devote greater time to it (2012: 12/3). Practices that make one miss meal times may be those which open up time for snacking. One's disposition may shape the type of snacks one consumes but also as important the sort of neighbouring practices one performs which may be bundled with snacking. This is important if snacking is a practice that is rarely done in isolation from other practices. 
Temporal procedures evoke tacit knowledge around, for example, how long practices are socially expected to last (such as breakfast during the week being a relatively quick meal) or the order in which they are expected to take place (breakfast, lunch, dinner). For Southerton "such temporal regularities coordinate and hold practices stable in ways that generate procedures of action" (2012: 14). Changing eating practices may involve opening up such tacit procedural knowledge to reflexive scrutiny in terms of the way in which temporal procedures are important in the regular reproduction of practice and to the way in which other practices may subtly effect change upon them. Other practices compete with eating for time and we could point to the way in which food preparation time has been squeezed and more processed foods have emerged recursively with this. If meals are becoming shorter events then perhaps this is another way in which meals and snacks become less bounded. Snacking as indicated above has its own temporal procedures guiding when and for how long it is expected to take place. If one consistently snacked at 'mealtimes' this would likely be deemed against prevailing food and nutritional norms. Snacks allow creativity in the everyday performance of the temporal procedure of eating events and in as much are productive, allowing for negotiation in everyday time management. Snacking is also assumed to be an eating practice of short duration. We can see here how a subversion of its own temporal procedure would likely bring snacking into clearer conflict with moralised meanings around norms of ordered and healthy eating.

Sequences are intended by Southerton to capture the way in which performances are shaped by material objects, infrastructure and institutionally timed events (2012: 14/5). We might think of the embodied performance of following a recipe and interacting with various technologies as an example of this, or how kitchen technologies such as the freezer, microwave or the food processor speed up performances. Processed snacks clearly benefit 
from technological innovations in production and distribution. Snacking practices also emerge within institutionally timed events such as the end of the school or work day, in designated break or play times via access to local shops or catering vans and during leisure time. Different modes of workplace catering infrastructure including the presence of vending machines or canteens also allow for flexibility over the timing of snacking performances.

Shove et al. and Southerton's conceptual framework give a closer account of the interrelationship between practices and temporalities, a better vantage point to consider how practices compete for time, how everyday performances take place within complex interweavings of practice and time, how practices configure temporalities and how temporalities shape practice (Shove et. al. 2012: 127-130, Southerton 2012: 16). Shove et. al. suggest that rather than straightforwardly competing against each other for time, "time is something that practices 'make'...experiences of time are part and parcel of the experience of practice" (2012: 129). Experientially this is a compelling framing as we come to grasp time through socially conventional everyday doings. The idea that practices have 'careers' adds to Southerton's work on temporality, recognising that "at any one moment, 'a practice' consists of a composite patchwork of variously skilled, variously committed practitioners enacted and reproduced by beginners and old-hands alike" (Shove et. al. 2012: 71). This helps capture the dynamism of a practice and is suggestive for research that might target differently positioned practitioners within the practice entity. For example, how might the emergence of childhood snacking differ within society (and between societies) and under what conditions do children transition to healthy snacking? I have already suggested that there is an element of time competition and colonisation between 'meals' and 'snacks'. Snacking can also 'make time' when it is used to break up the morning or afternoon and 
structure the working day. These temporal considerations greatly enhance the conceptualisation of snacking. However they require empirical research in, for example, the complex sites of family and workplace and their associated relationships. I briefly consider such research below.

\section{Researching Snacking}

First, it is worth noting how those with a commercial interest in reproducing and broadening the practice of snacking, the snacking industry, are interested in extending the practice in order to maximise sales. Indeed they have a degree of literacy around the relationship between eating and temporality. Every year the Snack Food Association (SFA), an international trade association formed in 1937, organises the annual SNAXPO 'The world's largest, most comprehensive trade show devoted exclusively to the international snack food industry'4. In 2014 Sally Wyatt from Information Resources Inc. (IRI) presented on the current state of the snack food industry -

"Wyatt stressed the impact of today's busy consumer who is increasingly eating more frequent, but smaller, meals throughout the day. While indulgent snack sales are still strong, she said sales of healthier-for-you snacks are continuing to increase. Wyatt advised snack manufacturers to take advantage of all day parts, tailoring products to the types of occasions they wish to target, from early morning to late at night, keeping in mind the snacking habits of age groups and other demographics",

This extract is interesting not only for the distinction made between 'indulgent' and 'healthier-for-you' snacks which acknowledges the growth in the latter category but also for 
the temporal awareness of the snack industry as they divide up the day (not unlike a quantitative time use approach) and target particular time slots which can potentially inhere in the materiality and meaning of the snack product.

This work on a practice conceptualisation of snacking begins to suggest empirical directions. From this extract one could begin to investigate how the marketing of snacks frames eating practices. Practice theory as a theory of process is obviously interested in historical approaches to understanding the dynamism of elements, practices, bundles and complexes. As part of a larger aim to understand the emergence and history of snacking, an important empirical project could be to research the emergence of bodies like the SFA and the role they may have played in further bringing together the elements of the practice. Another approach in this vein is to look at the history of specific food companies or food commodities, notably sugar (Abbott 2010; Mintz 1986) and salt (Kurlansky 2003), in order to trace their emergence and normalisation within everyday eating practices. This is further necessary in order to embed understandings of eating practices within a timeline of transnational political economy and political ecology, to keep relations of power at the forefront of the analysis of everyday (but not reducible to a micro scale) food performances and practices.

A historical approach to elements of a practice or to the forms of action in habitual performance offer further points of possible empirical research. This could include a history of potato crisps, chocolate bars, charting the more recent history of healthier snacks or indeed a material history of the aforementioned vending machine. This latter suggestion reminds us to retain a focus on the spatiality of practice alongside the focus on temporality. This adds to our understanding of both the meanings and sequences of performances. Institutional spatial norms are important here. For example, many though by no means all workplaces afford 
opportunities to snack with a great deal of flexibility. Some schools also allow a more limited degree of food or drink consumption outside meal times. As a practice is allowed to be performed in new spaces its normalisation becomes more secure. Working alone in an office would be one example that affords such freedom and largely removes one from the sort of activities or micropolitics of the work environment that could constrain personal food autonomy. The tendency for people to lunch in their office perhaps due to time constraints also reinvents the workspace as a site of food consumption where potentially less healthy snacks or snack-like meals are more likely to be consumed largely alone.

This is an example of the way in which practices not only 'make time' but also "re-make space" (Shove et. al. 2012: 133). If there has been a partial destructuration of the meal this may be accompanied by various spatial elaborations of eating events to different rooms in the house and within the rise of eating out. With such shifts we might expect materials associated with the family meal such as the dining table to take on new meanings, uses or indeed disappear (see Curtis et. al. 2010: 292). A consideration of space also clearly sets up potential sites for empirical investigation. Family households, workplaces, school spaces and spaces of mobility where people snack on the move, sites of leisure spectatorship are all obvious sites to target. Expanding markets have also allowed particular snacking practices to extend across space and to be performed transnationally. At any one time many people are performing snacking and constitute the same "practice-space" in spite of their dispersal (Shove et. al. 2012: 133). Yet if snacking is a practice that is especially bound up with others it is important not to decontextualise it from its neighbours but to think about the co-location of specific practice bundles that reproduce the practice entity. 
Considering space can serve to refine the ontological focus of practice theory. Although it may be implicit (because practices are self-evidently social) it is arguably more accurate to posit the social as constituted by practices and relations. It is people and their spatial networks that perform practices and bring together or prevent the important links forming between different elements of a practice. This is not meant as a humanist reassertion but as recognition of everyday human doings (relationally with the nonhuman) enmeshed in the reproduction of practices. Communities of practice are thus important for both verifying performance and innovating within and between practices (Shove et. al. 2012: 66/7 \& p.160), for exposure to new meanings and material forms and for learning new competences. Conversely, people and networks may act to block new practices by staying loyally with preexisting ways of doing and devaluing or blocking new niche innovations. Making relations explicit is also important for holding onto understandings of how power operates socially through the performance of practice and the deepening of practice entities in the context of sophisticated practice complexes.

It is possible to illustrate the interplay of relations and practice by returning to snacking and focussing upon one site, the family home. Unlike other eating practices most people practice snacking. It has successfully become a normal everyday eating event. The practice diversifies in terms of frequency, generation, timing, duration, location and material content. Snacking may also vary over the life course and in relation to disposition. Although 'family' households clearly reflect much diversity, research on families and food can be instructive for exploring further the interplay of familial relations and the practice of snacking.

Eating practices change as familial arrangements do (Jackson 2009: 3) such as a rise in single person households or in dual earner families (Brannen et. al. 2013). The dynamism in 
familial arrangements is in turn bound up in changing patterns of employment and in shifts in gendered social expectations and meanings in family and work life. A focus on children's eating practices illustrates how food is intimately part of the micropolitics of control within and between familial relations. This focus is important because it is often children's as opposed to an adult's or parent's snacking that is subject to moralisation. Researching children's eating practices can relate in turn to understanding further particular forms of 'doing family' (Morgan 2011: 5) and parenting modes (O'Connell and Brannen 2013), the threat that children's snacking might pose to the family meal, and to a particular ideology of 'family' as revolving around formality, hierarchy and traditional food (Curtis et. al. 2010).

The family home has long been seen by social scientists as an important site for social reproduction but translated into the terms of practice theory we can begin to specify how elements of a practice may circulate. If eating practices are part of doing family more specifically they can also be seen as part of the performances of childhood, parenthood and grandparenthood and they figure strongly in these negotiated everyday relationships. Relations are important for the circulation of dispositions, the reproduction of practice and its elements. Parents normalise the regular food materialities and meanings that a child first encounters and directly or not teach a child various food competences such as nutritional knowledge and by displaying their own eating performances (Marshall et. al. 2007: 168). These may be most conflicted in differences between children and grandparents reflecting generationally embedded moral assumptions about certain foods or eating events. Food performances may be especially salient in families co-produced by migration as elements also bundle with the performance of ethnicity and nationhood and are shaped by meaningful memories. Relations are inevitably about affiliation and power and so eating practices are also demonstrative of care and affection (Punch et. al. 2010: 227) and figure in conflict and 
control between parents and children (O'Connell and Brannen 2013). Snacking may be closely controlled by parents and may vary by their investment in meanings of healthy food. Children may snack at those times such as after school when they may be indulged or less likely to be observed or supervised.

Research that focuses on the perspectives of children has uncovered their role in shaping family eating practices and made clear their agency in securing snacks through request or even subterfuge as well as explicating examples of snacking bundling, perhaps most notably with TV viewing (Marshall et. al. 2007: 171-2). As we might expect from the earlier discussion on temporality research that focuses on time, food and family life is revealing for understanding the social organisation of eating events. In their study of meal times in British dual earner families Brannen et. al. revealed the complexity around attempts to perform a synchronous 'family meal'. They exposed important issues such as work time schedules, children's participation in extra-curricular activities, the ages of children and the coordination of differing family food preferences in making the family meal during the working week difficult to achieve consistently (2013: 429). What exact implication a lack of meal coordination may have on the nature of snacking events is a question for further research. This study demonstrates what Valentine has discussed as the connection between the home and other spaces (1999: 514) whereby domestic (food) practices may be the result of elements that have 'travelled' from elsewhere (such as new foodstuffs or meanings or techniques) and are shaped by the often rather fixed temporal sequences of the workplace or of leisure commitments.

This section briefly summarised various ways in which an analysis of one site, in this case the family household, can yield a closer understanding of the interplay of practices and relations, 
whilst at the same time recognising that no one site is bounded off from the broader dynamics of social practice. Alongside the historical approaches outlined earlier and the proposed analysis of the snacking industry this sort of social science research represents a third direction of inquiry informed by a practice theory approach. It underlines the need for in situ empirical social research to better comprehend the nuances of eating practices within and between social relations.

\section{Conclusion}

In considering what a practice theory approach might have to offer, this article has outlined the various ways in which the framing affords a new conceptualisation of snacking. The performance of snacking emerges not out of unruly behaviour but through the recruitment of practitioners to a type of eating event that has emerged in the social, temporal, economic and cultural organisation of everyday life.

Viewing snacking in terms of the three elements of practice - materialities, meanings and competences - it is possible to grasp the dynamism of the practice and to begin to consider how these elements have come to cohere in everyday recognisable 'normal' performances. This framing also partly addresses the definitional complexities that many have commented upon in the snacking literature. If a snack is partly a practice in temporal and material competition with the meal we can see its role in the proto destructuration of the meal as lunch and breakfast begin to take on snack-like material form and meaning. This element of categorical ambiguity seems to add methodological credibility to approaching everyday eating as a series of eating events or at minimum refraining from imposing categories upon 
the practices of the researched. To do so would be to risk missing out on innovative performances even though there remain normative temporalities and materialities to many of our everyday eating practices.

The practice approach also underlines the importance of historical research in order to learn more about how a practice entity emerges and several research avenues informed by the approach were suggested. Corporate practices for both framing and embedding snacking were suggested as especially important areas for research. Work around temporality and habit was presented to make clear that eating practices cannot be reduced to wholly autonomous rational choices but are embedded within relatively stable practice interdependencies. Southerton's elaboration of habits and routines as stable reflections of practices informed by dispositions, procedures and sequences afforded further conceptual gains in understanding the reproduction of snacking performances. With the intention of suggesting further empirical directions the importance of the interplay between relations and practices was explored through the example of the familial household.

Whilst practice theory is keen to stress how practices constitute the social they do so recursively with and through relations. Bringing together recent practice theory with the sociology of the family is a worthy intellectual development given that the latter has over the past twenty years conceptualised families as practices and dynamic performances (e.g. Morgan 1996, Curtis et. al. 2009: 94/5). It is within such highly porous social sites that locate the doing of work, education and family, and within the material practices of food manufacturers and retailers that we can begin to better understand the practice of snacking, its reproduction and, if appropriate, points of intervention. 


\section{Notes}

${ }^{1}$ This is the strapline of the UK DEMAND centre which investigates practices relevant to energy consumption, see http://www.demand.ac.uk/

${ }^{2}$ Although there do exist industry associated organisations such as the Snack Food Association (http://sfa.org/) and the European Snacks Association (http://www.esa.org.uk).

3 “'Healthy' breakfast bars? You might as well eat a Hobnob! Research reveals shocking levels of fat and sugar in 'on-the-go' snacks and low-fat yogurt', Daily Mail, $27 \quad$ October 2012 http://www.dailymail.co.uk/news/article-2224189/Healthy-breakfast-bars-You-eat-Hobnob-Research-revealsshocking-levels-fat-sugar-snacks-low-fat-yogurt.html\#ixzz32LeiN7fW

${ }^{4}$ See http://www.snaxpo.com/

${ }^{5}$ See http://www.iriworldwide.com/NewsEvents/PressReleases/ItemID/1868/View/Details.aspx

\section{References}

Abbots, E. and Lavis, A. (eds.) (2013) Why We Eat How We Eat-Contemporary Encounters between Foods and Bodies Farnham: Ashgate.

Abbott, E. (2010) Sugar: A bittersweet history. London: Bloomsbury Publishing.

Blue, S., Shove, E, Carmona, C. and Kelly, MP. (2014) Theories of Practice and Public Health: understanding (un)healthy practices, Critical Public Health, published online 12 Nov 2014.

Brannen, J., O'Connell, R. and Mooney, A. (2013) Families, meals and synchronicity: eating together in British dual earner families, Community, Work and Family, 16, 4, 417-434. 
Chamontin, A., Pretzer, G. and Booth, D. (2003) Ambiguity of 'snack' in British usage, Appetite, 41, 1, 21-29.

Curtis, P., James, A. and Ellis, K. (2010) Children's snacking, children's food: food moralities and family life, Children's Geographies, 8, 3, 291-302.

Delormier, T., Frohlich, KL. and Potvin, L. (2009) Food and Eating as Social Practice understanding eating patterns as social phenomena and implications for public health, Sociology of Health and Illness, 31, 2, 215-228.

Grogan, S, Bell, R. and Conner, M (1997) Eating Sweet Snacks: Gender Differences in Attitudes and Behaviour, Appetite, 28, 1, 19-31.

Guthman, J. and DuPuis, M. (2006) Embodying neoliberalism: economy, culture, and the politics of fat, Environment and planning D, 24, 3, 427-448.

Jackson, P. (ed) (2009) Changing Families, Changing Food. Basingstoke: Palgrave Macmillan.

James, A., Kjørholt, A-T. and Tingstad, V. (eds) (2009) Children, Food and Identity in Everyday Life. Basingstoke: Palgrave Macmillan.

Kurlansky, M. (2003) Salt: A World History. London: Vintage. 
Lang, T. (2009) Reshaping the Food System for Ecological Public Health, Journal of Hunger and Environmental Nutrition, 4, 3-4, 315-335.

Macdiarmid, J., Loe, J., Craig, LCA. and Masson, LF. et al. (2009) Meal and snacking patterns of school-aged children in Scotland, European Journal of Clinical Nutrition, 63, 11, 1297-1304.

Marshall, D., O'Donohoe, S. and Kline, S. (2007) Families, food, and pester power: beyond the blame game?, Journal of Consumer Behaviour, 6, 4, 164-181.

McCrory, MA. and Campbell, WW. (2011) Effects of eating frequency, snacking, and breakfast skipping on energy regulation: symposium overview, The Journal of Nutrition, 141, $1,144-147$.

Mestdag, I. (2005) Disappearance of the traditional meal: temporal, social and spatial destructuration, Appetite, 45, 1, 62-74.

Mintz, S. (1986) Sweetness and Power: the place of sugar in modern history. New York: Penguin.

Morgan, D. (2011) Rethinking Family Practices. Basingstoke: Palgrave Macmillan.

O'Connell, R. and Brannen, J. (2014) Children's food, power and control: Negotiations in families with younger children in England, Childhood, 21, 1, 87-102. 
Pickering, A. (2000) Practice and Posthumanism: social theory and a history of agency. In Schatzki, T, Knorr Cetina, K. \& von Savigny, E. (eds) The Practice Turn in Contemporary Theory. London: Routledge.

Probyn, E. (2000) Carnal Appetites: FoodSexIdentities. London: Routledge.

Punch, S., McIntosh, I. and Emond, R. (2010) Children's food practices in families and institutions, Children's Geographies, 8, 3, 227-232.

Reckwitz, A. (2002) Toward a theory of social practices, European Journal of Social Theory, $5,2,243-263$.

Røpke, I. (2009) Theories of practice - New inspiration for ecological economic studies on consumption, Ecological Economics, 68, 10, 2490-2497.

Savige, G., MacFarlane, A., Ball, K. and Worsley, A. et al. (2007) Snacking behaviours of adolescents and their association with skipping meals, International Journal of Behavioral Nutrition and Physical Activity, 4, 36.

Sayer, A. (2013) Power, Sustainability and well being: an outsider's view. In Shove, E. and Spurling, N. (eds) Sustainable Practices: Social Theory and Climate Change. London: Routledge.

Schatzki, T. (1996) Social Practices: A Wittgensteinian Approach to Human Activity and the Social. Cambridge: Cambridge University Press 
Southerton, D. (2006) Analysing the temporal organization of daily life: Social constraints, practices and their allocation, Sociology, 40, 3, 435-454.

Southerton, D. (2013) Habits, routines and temporalities of consumption: From individual behaviours to the reproduction of everyday practices, Time and Society, 22, 3, 335-355.

Valentine, G. (1999) Eating in: home, consumption and identity, The Sociological Review, $47,3,491-524$.

Verplanken, B. (2010) Beyond frequency: Habit as mental construct, British Journal of Social Psychology, 45, 3, 639-656.

Warde, A. (2013) What sort of a practice is eating?. In Shove, E. and Spurling, N. (eds) Sustainable Practices: Social Theory and Climate Change. London: Routledge.

Warde, A. and Yates, L. (2014) Understanding Eating Events: Snacks and the British Meal Pattern, forthcoming in Appetite

Weijzen, PLG., de Graaf, C. and Dijksterhuis, GB. (2009) Predictors of the consistency between healthy snack choice intentions and actual behaviour, Food Quality and Preference, 20, 2, 110-119. 
